Human Factors: The Journal of the Human Factors and Ergonomics Society

Topic choice : Biomechanics, Anthropometry, Work Physiology

\title{
Effects of anthropometric variables and seat height on automobile drivers' preferred posture with the presence of the clutch
}

Junfeng Peng,a,b,d,, Xuguang Wang ${ }^{\mathrm{a}, \mathrm{b}, \mathrm{c}^{*}}$, Lisa Denninger ${ }^{\mathrm{d}}$

a Université de Lyon, F-69622, Lyon, France

${ }^{b}$ Université Claude Bernard Lyon 1, Villeurbanne

'IFSTTAR, UMR_T9406, LBMC Laboratoire de Biomécanique et mécanique des chocs, F69675,Bron;

${ }^{d}$ PSA Peugeot-Citroën, Sochaux

Total words :4450

- Introduction : 1279

- Materials and Mathods : 1276

- Results : 549

- Discussion : 1455

- Conclusion : 193

* Corresponding author: Xuguang Wang, LBMC-Ifsttar, 25 av. F. Mitterrand, case 24, 69675 BRON Cedex, France

Tel: +33 (0)4.72.14.24.51

Fax: +33 (0)4.72.14.23.60

Email: xuguang.wang@ifsttar.fr 
Human Factors: The Journal of the Human Factors and Ergonomics Society

\section{PRÉCIS/SHORT ABSTRACT ( $<50$ words)}

The effects of seat height and anthropometric dimensions on drivers' preferred postures were investigated using a multi-adjustable vehicle mock-up with a high number of adjustments and extended ranges. Data were collected from 61 subjects testing 4 seat heights. Hip and eye positions as well as inter segmental angles were analyzed. 
Human Factors: The Journal of the Human Factors and Ergonomics Society

\section{Abstract}

Objective: The effects of seat height and anthropometric dimensions on drivers' preferred postures were investigated using a multi-adjustable vehicle mock-up with a high number of adjustments and extended ranges.

Background: Many studies have been conducted on preferred driving posture under different test conditions showing mixed and even contradictory findings. No studies thusfar have considered the clutch and compared Chinese and European drivers.

Methods: Four seat height conditions were tested: free and three imposed heights (H30=250, 300 and 350 mm). Sixty-one subjects (40 'French-born' and 21 'Chinese-born') participated in the experiment, covering a large range of stature and sitting height to stature ratio. The RAMSIS kinematic model was used to reconstruct postures and main inter segmental angles were extracted for characterizing posture.

Results: Under the free seat height condition, no significant differences in preferred intersegmental angles were observed between different participant groups. Seat height mainly affected trunk-thigh angle, while it had almost no effect on trunk orientation and other inter segmental angles. Chinese participants sat more forward in the seat leading to a more opened trunk-thigh angle and a more reclined trunk.

Conclusions: Results suggest that inter-segmental angles of preferred posture are not dependent on anthropometric dimensions, though shorter drivers prefer a slightly less reclined trunk. Self-selected driving posture results from a compromise between maintaining the intersegmental angles in their preferred range and a preferred trunk orientation in space.

Applications: The findings contribute to a better understanding of preferred driving postures and would be helpful for improving vehicle interior design.

\section{Keywords}

Automotive, Driving posture, Anthropometry, Digital human modeling, Vehicle packaging 
Human Factors: The Journal of the Human Factors and Ergonomics Society

\section{Introduction}

In order to optimize vehicle interior layout and to accommodate a large population with a high variation of anthropometric dimensions, knowledge about drivers' preferred postures is required. Many studies (see Schmidt et al. 2014 for a review) were investigated under different laboratory conditions with a higher number and a larger range of vehicle interior adjustments than those in a real vehicle. Different ranges of preferred joint angles are suggested. Taking trunk-thigh angle as example, Porter and Gyi (1998) suggested a range between $90^{\circ}-115^{\circ}$, while Hanson and al. (2006) proposed $68^{\circ}-99^{\circ}$. After filtering data based on subjective ratings of comfort and discomfort, Kyung and Nussbaum (2009) recommended two discontinued subranges for the right side, $83^{\circ}-92^{\circ}$ and $112-123^{\circ}$ for sedan-type vehicles. Preferred posture is a choice among all possible postures allowed by experimental conditions. As long as one or more adjustments are available, the adopted posture can be considered as the preferred one. It is therefore important to specify the experimental conditions used for identifying preferred posture. Different ranges of preferred joint angles may be due to differences in experimental conditions. Table 1 summarizes the experimental conditions, in particular, the number of available adjustments and their range for seven past studies investigating drivers' preferred posture.

Two experimental categories can be distinguished, one with very few vehicle parameters being fixed and all others being adjustable by participants themselves, and one with few parameters being adjustable and all others being pre-defined with respect to vehicle class (e.g. SUV, Sedan, Sports car, Truck). The studies by Richouchon (1991), Porter et al. (1998) and Hanson et al. (2008) belong to the first category, while those by Seidl (1994), Kyung and Nussbaum (2009) and Reed et al. (2000) fall into the second one. Seidl (1994) and Kyung and Nussbaum (2009) studied the effect of vehicle configurations with the seat height being predefined. Reed et al (2000) performed a parametric study with 18 combinations of seat height, fore-aft steering position and seat cushion angle. In addition to the difference in the number of adjustable parameters, the range of adjustment of the parameters studied in past investigations could be very different as well as the way of adjustment. In the work by Hanson et al. (2006), seat height varied from $-20 \mathrm{~mm}$ to $265 \mathrm{~mm}$, close to the range for a sports car. Preferred seat height from 38 participants was observed at $181 \mathrm{~mm}$ on average. Porter and Gyi (1998) observed that preferred seat height was between 283 and $335 \mathrm{~mm}$ with an average of $301.1 \mathrm{~mm}$, though the range of seat height adjustment was not explicitly reported. The way of carrying out adjustments for finding a preferred posture could be very critical, especially when participants 
Human Factors: The Journal of the Human Factors and Ergonomics Society

are asked to adjust a high number of parameters. In the studies by Ribouchon (1991) and Hanson et al. (2006), most adjustable parameters were motorized and could be easily changed by participants themselves, whereas the mock-up used in Porter and Gyi (1998) was only manually adjustable mainly with help of experimenters. It can be noticed that a road screen was used to simulate vision while driving in some studies (Seidl, 1994; Porter and Gyi 1998; Reed et al. 2000, Hanson et al. 2006, Kyung and Nussbaum 2009), while subjects were only required to look forward as driving in other studies. The presence of a screen may affect preferred posture if its location is not freely chosen.

Due to differences in experimental conditions between existing studies, it's difficult to compare the observed results. Some observations were even contradictory, especially for the effect of stature. Park and his colleagues (1999) found trunk-thigh angle was positively correlated with stature, while in another publication (Park et al. 2000), a negative correlation was found. Porter and Gyi (1998) observed a more ‘open’ posture for taller subjects with bigger elbow and trunk-thigh angles. But they explained that this could be due to the limited adjustment ranges of the rig. Ribouchon (1991) observed that the driver's preferred posture under the condition of free seat height was not dependent on stature. This was confirmed by a more recent study by Hanson et al. (2006), who found no significant difference in postural angles between short (stature $<170 \mathrm{~cm}$ ) and tall subjects (stature $>190$ ). Besides, the effect of the experimental conditions, especially seat height, on drivers' preferred posture was rarely discussed. In addition, most of published studies were performed using an experimental set-up without the clutch pedal. For example, the statistical predictive models proposed by Reed and his colleagues (Reed et al, 2002 and Park et al, 2016) are based on data without considering the clutch pedal. They may not be applicable to the vehicles with the clutch, knowing that the majority of vehicles in Europe, particularly in France, have the clutch.

As far as subjects are concerned, most of the previous studies were conducted among Europeans or North Americans, but there were few studies involving Asian participants, especially Chinese drivers. There was no investigation comparing drivers' preferred postures between two different populations in a same study. Anthropometric characteristics of Chinese adults are different from French people not only in stature, but also in body segment proportion. For example, according to a anthropometric survey of Chinese adults in 1988 (GB10000-88), the mean stature of Chinese males is $1678 \mathrm{~mm}$ against $1719 \mathrm{~mm}$ for French males drivers (Rebiffé et al 1982). For sitting height, the mean values are 908 and $911 \mathrm{~mm}$ respectively for Chinese and French males with a much smaller difference, suggesting that sitting height to stature ratio is also different between these two populations. Among the few studies involving 
Human Factors: The Journal of the Human Factors and Ergonomics Society

Asian population, Park et al. (2000) investigated comfortable driving postures for Koreans. They observed greater trunk-thigh and knee angles than those recommended in the literature and concluded that there might be a difference in preferred driving posture between Koreans and Caucasians. Kyung (2008) collected drivers' preferred postures and subjective evaluations of 11 North Americans and 11 Koreans in a laboratory environment using an adjustable driving mockup. A significant difference in whole body discomfort ratings between the two groups was observed, but postures were not compared. As China is the now the world's largest automobile market, one may wonder whether the existing recommendations and practices mainly based on the past data collected from Europeans or North Americans could be applied to Chinese market.

Digital human models (DHMs) are now used by vehicle design engineers especially at the early phase of design for assessing the ergonomics of a future vehicle (see Duffy, 2009 for an overview on DHMs). One of key questions posed by design engineers is which comfortable posture to be used. Should it be body size and vehicle segment dependent? As vehicles of different segments are mainly differentiated by seat height, the question about effects of seat height are posed. But past studies showed quite contradictory results on the effect of stature as illustrated in the literature review. We doubted that this might be due to the difference in experimental conditions. No results on effects of seat height were published. To clarify the effects of anthropometric dimensions and seat height on drivers' preferred posture, an experimental study was conducted in the present work. The main purpose of this study was to answer the following research questions: (1) Is there a unique optimum driving posture if subjects are free to change all interior dimensions? More specifically, is there a unique preferred seat height for a person if seat height is free to adjust? (2) Does driver's preferred posture depend on anthropometric dimensions? More specifically, are preferred inter-segmental angles and trunk orientation body size dependent? (3) Is there any effect of seat height on preferred posture? If so, how does it affect preferred posture? 
https://dx.doi.org/10.1177/0018720817741040

Human Factors: The Journal of the Human Factors and Ergonomics Society

Table 1 Overview of the experimental conditions of the seven past studies on preferred/comfortable driving posture. Only the authorized adjustments by subjects are listed. Units are $\mathrm{mm}$ for distance and degree for angles.

\begin{tabular}{|c|c|c|c|c|c|c|c|c|c|c|}
\hline & & $\begin{array}{l}\text { Ribouchon } \\
\text { (1991) }\end{array}$ & $\begin{array}{l}\text { Seidl } \\
(\mathbf{1 9 9 4 )}\end{array}$ & $\begin{array}{l}\text { Porter et } \\
\text { al. (1998) }\end{array}$ & $\begin{array}{l}\text { Park et al. } \\
(2000)\end{array}$ & $\begin{array}{l}\text { Reed et al. } \\
(2000)\end{array}$ & $\begin{array}{l}\text { Hanson et } \\
\text { al.(2006) }\end{array}$ & $\begin{array}{l}\text { Kyung et al. } \\
\text { (2008) }\end{array}$ & $\begin{array}{l}\text { Park et al. } \\
(2016)\end{array}$ & Present study \\
\hline \multirow[t]{2}{*}{ Origin } & Fore/aft & H-point & & AHP & AHP & BOF & AHP & & BOF & APC \\
\hline & vertical & Floor & & AHP & AHP & AHP & AHP & & $\mathrm{AHP}$ & Floor \\
\hline \multirow[t]{8}{*}{ Seat } & Fore/aft & & $x$ & $738-889^{c}$ & $x$ & $x^{a}$ & $701-1141^{a}$ & $x$ & $x^{a}$ & $500-1200^{a}$ \\
\hline & Vertical & $168-592^{\mathrm{a}}$ & & $283-335^{c}$ & & & $-20-265^{a}$ & & $x^{a}$ & $150-500^{\mathrm{a}}$ \\
\hline & Back angle & $-4^{\circ}-34^{\circ}$ a & $x$ & $5^{\circ}-25^{\circ \mathrm{c}}$ & $x$ & $x^{b}$ & $20.1^{\circ}-35.1^{\circ b}$ & $x$ & $x^{a}$ & $0-70^{\circ} \mathrm{a}$ \\
\hline & $\begin{array}{l}\text { Cushion } \\
\text { angle }\end{array}$ & $-0.5^{\circ}-32^{\circ}$ a & & $\times$ & $x$ & & & $x$ & $x^{a}$ & $0-30^{\circ}$ a \\
\hline & Cushion & & & & & & $x^{b}$ & & & $364-399^{b}$ \\
\hline & length & & & & & & & & & \\
\hline & Lumbar & $x^{a}$ & & $x$ & & & & & & \\
\hline & $\begin{array}{l}\text { support } \\
\text { Back } \\
\text { support }\end{array}$ & $x^{a}$ & & & & & & & & \\
\hline \multirow[t]{3}{*}{ SW } & Fore/aft & $229-489$ & & $322-602^{c}$ & $x$ & & $193-493^{a}$ & $x$ & & $300-1000^{b}$ \\
\hline & Vertical & $371-817^{a}$ & & $580-689^{c}$ & $x$ & & $373-625^{a}$ & & & $500-1000^{a}$ \\
\hline & angle & $0-87^{\circ}$ a & & & $x$ & & & $x$ & & $0-90^{\circ \mathrm{b}}$ \\
\hline \multirow[t]{3}{*}{ Clutch P. } & Fore/aft & & & unknown & & & unknown & & & $-100-200^{a}$ \\
\hline & Vertical & & & unknown & & & unknown & & & $0-300^{\mathrm{a}}$ \\
\hline & Travel angle & & & unknown & & & unknown & & & $9^{\circ}-37^{\circ \mathrm{c}}$ \\
\hline \multirow[t]{2}{*}{ Gas $P$. } & Fore/aft & & & $x^{c}$ & & & $x^{a}$ & & & \\
\hline & Vertical & & & $x^{c}$ & & & $x^{a}$ & & & $0-300^{c}$ \\
\hline \multirow[t]{2}{*}{ Foot R. } & Fore/aft & $705-943^{\text {a }}$ & & unknown & & & & & & $-100-300^{a}$ \\
\hline & Angle & $27^{\circ}-56^{\circ \mathrm{a}}$ & & unknown & & & $45^{\circ}-60^{\circ}$ a & & & $29^{\circ}-60^{\circ \mathrm{c}}$ \\
\hline Vision & & $\begin{array}{l}\text { Looking } \\
\text { forward }\end{array}$ & & Video & $\begin{array}{l}\text { Looking } \\
\text { ahead }\end{array}$ & Video & Video & Video & $\begin{array}{l}\text { Looking } \\
\text { forward }\end{array}$ & $\begin{array}{l}\text { Looking } \\
\text { forward }\end{array}$ \\
\hline Conditions & & $\begin{array}{l}9 \text { seat heights, } \\
\text { FSH }\end{array}$ & $\begin{array}{l}\text { Sports car } \\
\text { Sedan/Van }\end{array}$ & FSH & $\begin{array}{l}1 \text { seat } \\
\text { height }\end{array}$ & 19 & FSH & $\begin{array}{l}\text { Sedan, } \\
\text { SUV }\end{array}$ & 9 & $\begin{array}{l}3 \text { seat heights, } \\
\text { FSH }\end{array}$ \\
\hline \multirow[t]{3}{*}{ Participants } & $\mathrm{M} / \mathrm{F}$ & $34 / 11$ & $23 / 24$ & $28 / 27$ & $24 / 19$ & 68 & $17 / 21$ & $27 / 11$ & $43 / 47$ & $36 / 25$ \\
\hline & Stature & $1520-1910$ & & $1475-2002$ & $1510-1829$ & $1500-1900$ & $1610-1960$ & & $1452-1984$ & $1490-2000$ \\
\hline & Ethnic & French & German & British & Korean & American & Swedish & American & American & French /Chinese \\
\hline
\end{tabular}


Human Factors: The Journal of the Human Factors and Ergonomics Society

$\times$ the adjustment was available, but its range was not known. ${ }^{\text {a }}$ motorized adjustment; ${ }^{\mathrm{b}}$ manual adjustment by subject; ${ }^{\mathrm{c}}$ manual adjustment by experimenter at the request of subjects; not indicated if unknown; AHP=Accelerator Heel Point; BOF= Ball of Foot; SW = Steering Wheel center location. APC: Accelerator Pedal Center. H-point= a seat reference point defined according to SAE J826, FSH=Free Seat Height 


\section{Materials and methods}

\section{Participants}

Thirty-six males and twenty-five females, recruited mainly based on stature and sitting height, participated in the experiment. They all had a driving license for more than one year and drove regularly. They did not suffer any neurological or musculoskeletal disorders. In order to have a large variation of sitting height to stature ratio, an effort was made to constitute two comparable groups according to birth place: Chinese and French. Due to recruitment difficulty, most of Chinese participants were in the short and average stature groups, none of them was taller than $1805 \mathrm{~mm}$. The experimental protocol was approved by the ethical committee of IFSTTAR (French Institute of Science and Technology for Transport, Development and Networks). Informed consent was given before participating in the experiment.

Table 2. Main characteristics (Means \pm standard deviations) of participants by stature and by ethnic origin.

\begin{tabular}{|c|c|c|c|c|c|c|}
\hline Group & $\mathrm{M} / \mathrm{F}$ & $\begin{array}{c}\text { Stature (S) } \\
\quad(\mathrm{mm})\end{array}$ & $\begin{array}{l}\text { Sitting } \\
\text { Height } \\
(\mathrm{SH}) \\
(\mathrm{mm})\end{array}$ & $\begin{array}{c}\text { Buttock- } \\
\text { knee length } \\
\text { (mm) }\end{array}$ & $\begin{array}{l}\mathrm{SH} / \mathrm{S} \\
\left(10^{-2}\right)\end{array}$ & $\begin{array}{c}\text { Weight } \\
\text { (kg) }\end{array}$ \\
\hline Short & $1 / 19$ & $1582 \pm 41$ & $859 \pm 23$ & $557 \pm 22$ & $54.3 \pm 1.2$ & $54.4 \pm 7.5$ \\
\hline Average & $14 / 6$ & $1715 \pm 32$ & $915 \pm 29$ & $591 \pm 19$ & $53.4 \pm 1.5$ & $67.0 \pm 8.8$ \\
\hline Tall & $21 / 0$ & $1846 \pm 62$ & $960 \pm 26$ & $631 \pm 29$ & $52.0 \pm 1.3$ & $74.3 \pm 11.2$ \\
\hline All & $36 / 25$ & $1717 \pm 119$ & $912 \pm 49$ & $594 \pm 39$ & $53.2 \pm 1.6$ & $65.4 \pm 12.4$ \\
\hline French* & $12 / 15$ & $1683 \pm 88$ & $897 \pm 46$ & $588 \pm 24.2$ & $53.3 / 1.3$ & $63.1 \pm 9.4$ \\
\hline Chinese & $11 / 10$ & $1657 \pm 86$ & $899 \pm 40$ & $568 \pm 29$ & $54.3 / 1.1$ & $59.8 \pm 10.6$ \\
\hline
\end{tabular}

*Only participants with a stature less than $1805 \mathrm{~mm}$ were considered

For data analysis, the subjects were divided into three groups according to stature with about 20 participants per group: short, average and tall. A sub-sample of French participants was constituted by excluding those taller than $1805 \mathrm{~mm}$ for comparing French and Chinese participants. The main characteristics of the participants according to stature and ethnic origin are described in Table 2. There were no significant differences in stature and body weight between the two ethnic groups ( $p>0.05)$, while significant difference $(p<0.01)$ was found on sitting height/stature ratio. 
Human Factors: The Journal of the Human Factors and Ergonomics Society

\section{Experimental facilities}

A multi-adjustable vehicle mockup, shown in Figure 1 and Figure 2, was used. It was composed of an accelerator pedal, a clutch pedal, a foot rest, a steering wheel and a seat. The available adjustments are listed in Table 3. Most of them were motorized and could be controlled by subjects easily through a touch-screen, while others were controlled manually by themselves or an experimenter. The accelerator pedal height being adjustable by participants, the ball of foot reference point (BOFRP) defined in SAE J4004 was not thus fixed, the accelerator pedal center (APC) was used as origin for the longitudinal $\mathrm{x}$-axis. The vertical zaxis was defined as perpendicular to the floor.
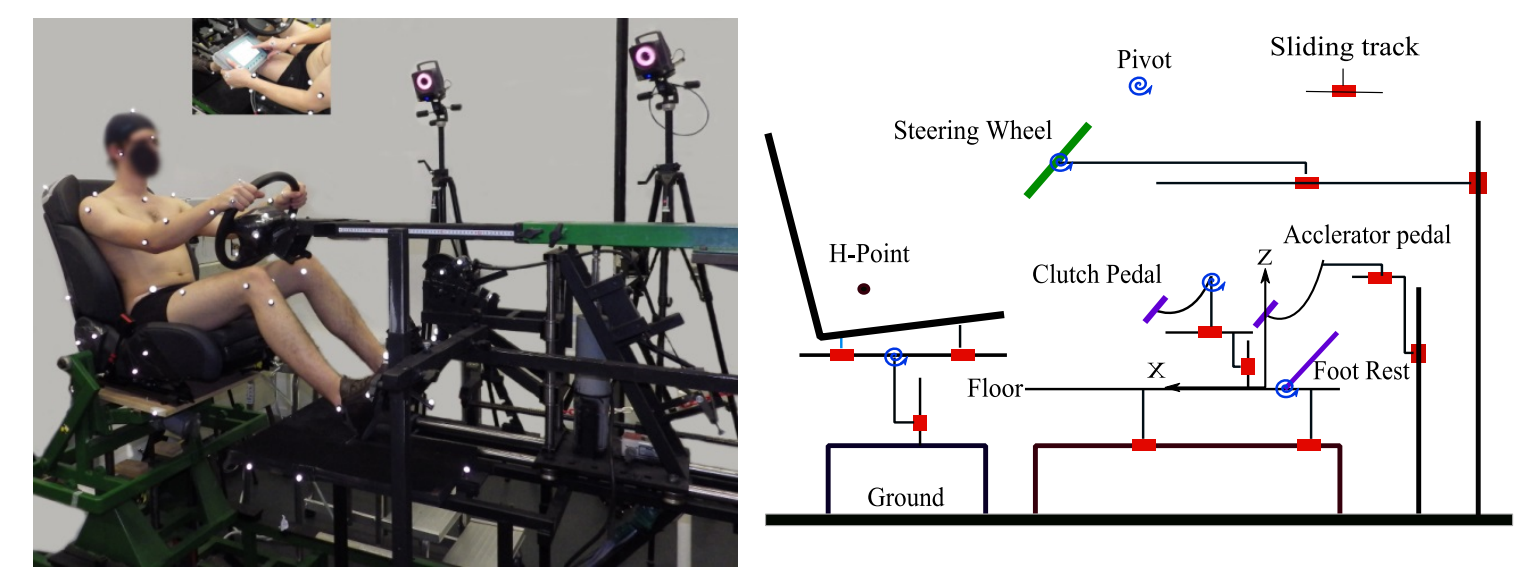

Figure 1. Experimental vehicle mock-up. All adjustable parameters except those of the seat are illustrated. 
Human Factors: The Journal of the Human Factors and Ergonomics Society

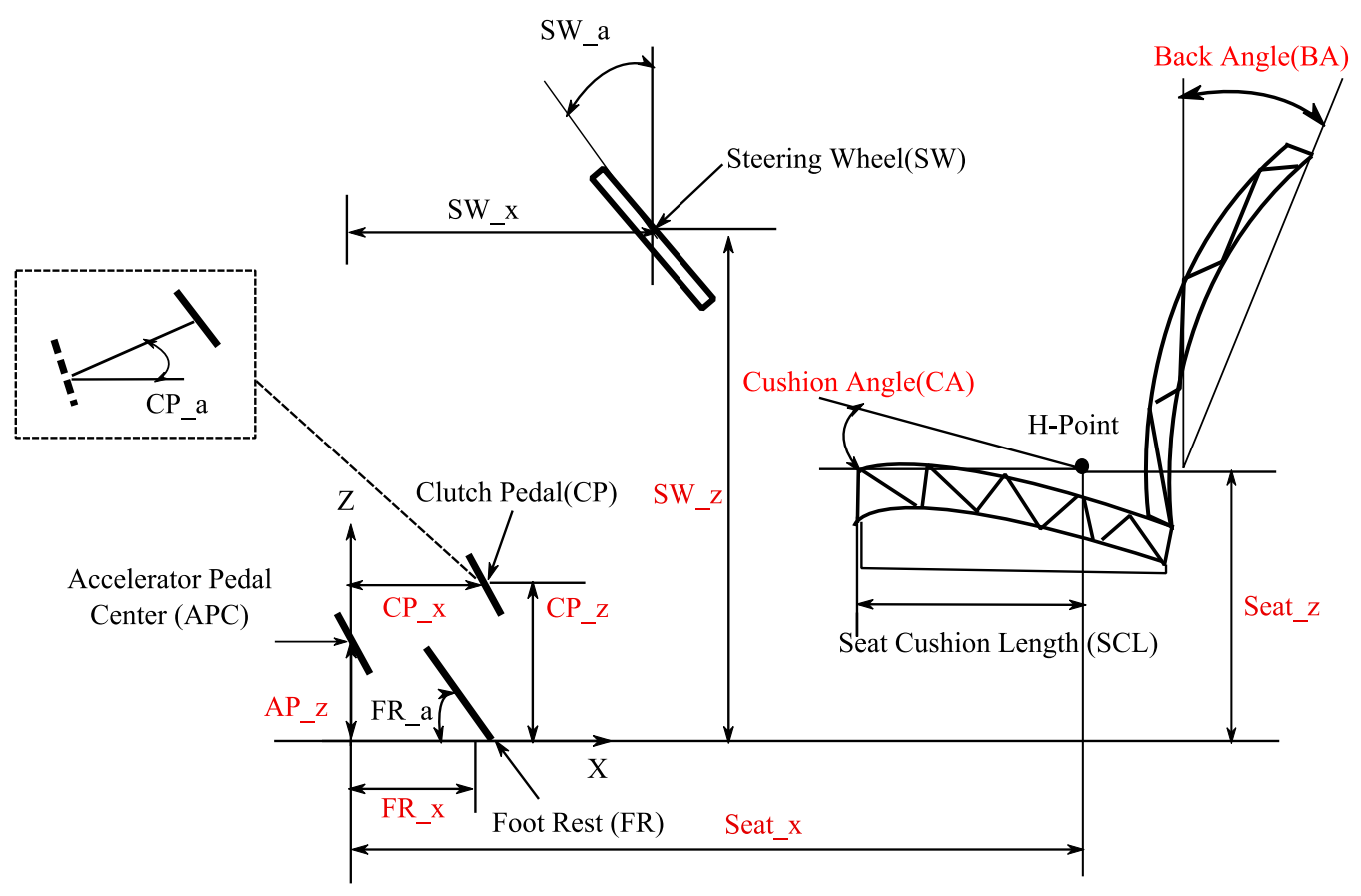

Figure 2. Illustration of adjustable dimensions of experimental vehicle mock-up, red for the motorized adjustments and black for manual ones by subject or experimenter.

Table 3. List of adjustable vehicle interior parameters of the mockup. Units are $\mathrm{mm}$ for distance and degree for angles.

\begin{tabular}{|c|c|c|c|c|}
\hline Adjustable Parameter & Abbreviation & Type of control & Min & Max \\
\hline Seat H-point - Floor, vertical & Seat_z & Touch-screen & 150 & 500 \\
\hline Cushion angle & CA & button or touch-screen & $0^{\circ}$ & $30^{\circ}$ \\
\hline Seat H-point - APC, horizontal & Seat_x & button & $<500$ & $>1200$ \\
\hline Back angle & $\mathrm{BA}$ & button & $0^{\circ}$ & $70^{\circ}$ \\
\hline Seat cushion length & SCL & Manual by subject & 364 & 399 \\
\hline Steering Wheel - floor, vertical & SW_z & Touch-screen & $<500$ & $>1000$ \\
\hline $\begin{array}{l}\text { Steering Wheel - APC, } \\
\text { horizontal }\end{array}$ & SW_x & Manual by subject & $<300$ & $>1000$ \\
\hline Steering wheel angle & SW_a & Manual by subject & 0 & 90 \\
\hline $\begin{array}{l}\text { Accelerator Pedal - Floor, } \\
\text { vertical }\end{array}$ & $\mathrm{AP}_{-} \mathrm{z}$ & Touch-screen & 0 & 300 \\
\hline Clutch Pedal - APC, horizontal & $\mathrm{CP}_{-} \mathrm{x}$ & Touch-screen & $<-100$ & $>200$ \\
\hline Clutch Pedal - Floor, vertical & $\mathrm{CP}_{-} \mathrm{z}$ & Touch-screen & 0 & 300 \\
\hline Clutch Pedal travel angle & CP_a & $\begin{array}{l}\text { Manual } \\
\text { experimenter }\end{array}$ & $9^{\circ}$ & $37^{\circ}$ \\
\hline Footrest - APC, horizontal & FR_x & Touch-screen & $<-100$ & $>300$ \\
\hline Foot rest angle & FR_a & $\begin{array}{l}\text { Manual } \\
\text { experimenter }\end{array}$ & $29^{\circ}$ & $60^{\circ}$ \\
\hline
\end{tabular}


Human Factors: The Journal of the Human Factors and Ergonomics Society

A Peugeot 508 seat, considered as a high-end product with electric adjustments in fore-aft position, height, lumbar support, cushion angle and back inclination, was used. Its cushion length was also adjustable from 364 to $399 \mathrm{~mm}$, measured horizontally from the seat front edge to the H-point. The seat track was mounted on a platform adjustable both in height and inclination, providing an adjustable seat height from about $150 \mathrm{~mm}$ to $500 \mathrm{~mm}$. An extended range of seat adjustment in $\mathrm{x}$ was ensured by moving the accelerator pedal in addition to the adjustment range of $240 \mathrm{~mm}$ of seat track itself. Seat cushion angle could be adjusted by its own tilt mechanism with a range up to $5^{\circ}$. If a larger rotation was required, the platform on which was mounted the seat track could also be rotated. Large seat back ranged from the vertical to almost the horizontal. The $\mathrm{H}$-point machine was used to measure the seat $\mathrm{H}$ point, cushion angle and back angle according to SAE J826.

The steering wheel was mounted on a separate pillar, providing a large adjustment range in both $\mathrm{x}$ and $\mathrm{z}$ directions. The clutch pedal was also adjustable in $\mathrm{x}$ and $\mathrm{z}$ independently. Clutch pedal travel angle could be chosen from five predefined values: $9^{\circ}, 16^{\circ}, 23^{\circ}, 30^{\circ}$ and $37^{\circ}$. Its travel length was fixed as $150 \mathrm{~mm}$ and its resistance at the end of depression was not explicitly controlled as in our earlier studies (Wang et al, 2000, Pannetier and Wang, 2014) as it did not affect the driving posture. The fore-aft position the foot rest could also be changed as well as its inclination. There were five discontinuous foot rest inclinations: $29^{\circ}, 36^{\circ}, 43^{\circ}, 51^{\circ}$ and $60^{\circ}$. No brake pedal was mounted.

Reflective markers were attached to the body and also to each of the adjustable elements (see Figure 1). 3D geometry of the all elements of the mock up as well as the attached markers were previously scanned by a portable handheld laser scanner (Nikon, ModelMaker MMD x /MMC Handheld Scanner). A VICON optoelectronic system with 14 MX40 cameras sampled $100 \mathrm{~Hz}$ was used to record the 3D location of the reflective markers during the experiment.

\section{Experimental conditions and procedure}

Four seat height conditions were tested in this study: free and three imposed seat heights. For the free seat height condition (FSH), all adjustments listed in Table 3 were all allowed. Seat height was initially placed extremely low (about $150 \mathrm{~mm}$ ) or extremely high (about $450 \mathrm{~mm}$ ), determined randomly prior to experiment. For the imposed seat height condition, three seat heights at 250, 300 and $350 \mathrm{~mm}$ were tested, covering a large range of passenger vehicles. Only the configuration with a seat height of $300 \mathrm{~mm}$ was tested three times for each participant for examination of intra individual variability. After the FSH condition, the test order of three heights was randomized. For each condition, subjects were asked to find their preferred driving 
Human Factors: The Journal of the Human Factors and Ergonomics Society

vehicle interior dimensions by changing all available adjustments with the fore-aft position of the accelerator being fixed.

After the arrival of a participant in the motion capture room, the purpose of the experiment was first explained. Then, he/she was asked to change into a gym-suit and 32 anthropometric measurements were collected. Reflective markers were attached to the body. Each participant was photographed in 4 different views in both a standing and a sitting posture in a calibrated space. These postures were also captured with the motion capture system for motion reconstruction. Each subject with attached markers was also scanned in a standing position by a 3D body scanner (SIMCAD II, Telmat industrie, Renesson, 2012).

For each test condition, initial positions of interior vehicle elements were set to their extreme positions randomly so that participants had to use all available adjustments. An adjustment sequence was suggested but not mandatory: accelerator pedal (only vertical position), seat (fore-aft position, cushion angle, back angle), footrest (for-aft position, inclination), clutch pedal (fore-aft position, vertical position, travel inclination), steering wheel (vertical and fore-aft position, inclination) and final fine adjustment. Participants were free to go back to the previous steps at any moment. They could take as much time as they needed to find their preferred adjustments. The process for finding preferred adjustment was quite long due to high number of the adjustable parameters. It could take more than 10 minutes for the FSH condition. Once subjects found their preferred driving position, a full movement of depressing the clutch pedal was recorded by the Vicon motion caption system. They were instructed to place their hands on the steering wheel at the 10-to-2 o'clock position and to look forward as they were driving naturally. No other visual constraints, other than looking forward, were imposed. They were asked to put their left foot on the foot rest, to fully depress the clutch pedal to its end, and then to move the left foot back on the foot rest. Subjects were asked to put the right foot on the accelerator without depressing. Subjects were required to leave the seat after each trial and the adjustments were reset for a new test configuration.

\section{Data processing and analysis}

All captured motions were reconstructed using the RAMSIS human model by minimizing the distance between the captured and model-based markers positions (see Ausejo and Wang 2008, for the principle of motion reconstruction). A set of postural parameters, defined in Table 4 and illustrated in Figure 3 were calculated from reconstructed joint centers for describing the driving postures at the rest (Re), beginning (De) and end of clutch pedal depression (Fi). In this 
Human Factors: The Journal of the Human Factors and Ergonomics Society

paper, if not explicitly indicated, postural variables at the rest position are given for which the left foot was on the foot rest and the right foot on the accelerator pedal without depressing.

Two-way analysis of variance (ANOVA) was used to assess the effect of participant group either by stature (SG) or by ethnic origin (OG), and seat height (SH). P-value at 0.05 was considered as significant for statistical tests. Because the postural angles of the left side are highly correlated with those of the right side, only the values of right side are listed when these effects are assessed. When testing the effect of ethnic group, a sub-sample of French participants was used by excluding those taller than $1805 \mathrm{~mm}$.

Table 4. Definition of the main driving posture variables

\begin{tabular}{|c|c|}
\hline Variables & Definition \\
\hline Hip_x, Hip_z & $\begin{array}{l}\text { Horizontal and vertical position of hip joint center with respect to } \\
\text { accelerator pedal center }\end{array}$ \\
\hline Eye_x, Eye_z & $\begin{array}{l}\text { Horizontal and vertical position of eye with respect to accelerator } \\
\text { pedal center }\end{array}$ \\
\hline Hip-to-Eye & $\begin{array}{l}\text { Angle between the vertical and the line passing through the mid of two } \\
\text { hip joint centers and that of eyes }\end{array}$ \\
\hline Trunk & $\begin{array}{l}\text { Angle between the vertical line and the line passing through the center } \\
\text { of left-right hip joint centers and that of right-left shoulder joint centers. }\end{array}$ \\
\hline R(L)_Trunk-thigh & Angle between hip-knee and hip-shoulder lines at the right (left) side \\
\hline R(L)_Knee & Angle between knee-ankle and knee-hip lines at the right (left) side \\
\hline R(L)_Shoulder & $\begin{array}{l}\text { Angle between shoulder-elbow and shoulder-hip lines at the right (left) } \\
\text { side }\end{array}$ \\
\hline R(L)_Elbow & $\begin{array}{l}\text { Angle between elbow-wrist and elbow to shoulder lines at the right } \\
\text { (left) side }\end{array}$ \\
\hline
\end{tabular}




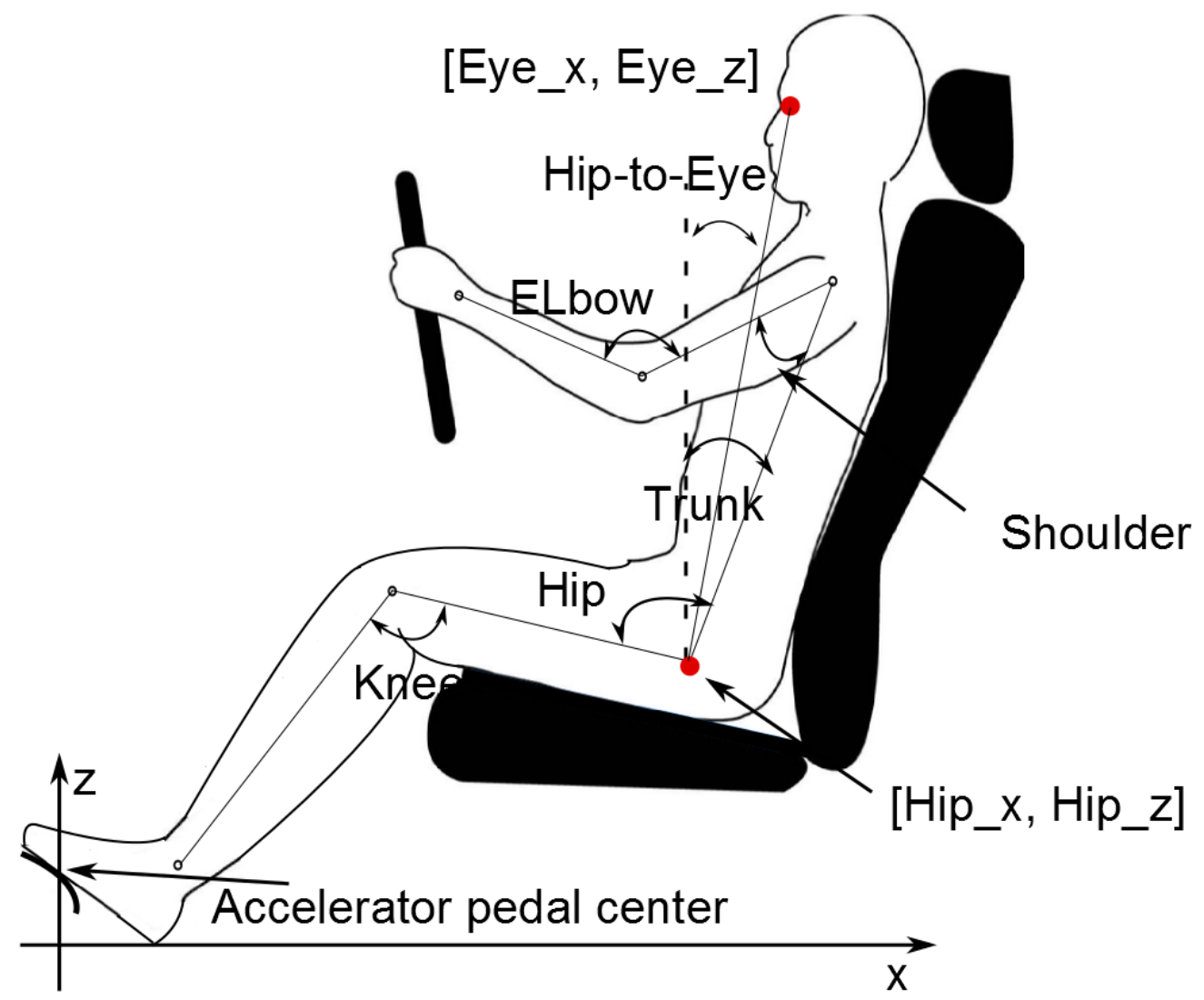

Figure 3. Definition of postural variables

\section{Results}

\section{Intra and inter individual variability}

The test condition with an imposed seat height at $300 \mathrm{~mm}$ was repeated three times. For each response, the maximal difference between three repetitions for each participant was calculated as the intra-individual variability. Table 5 presents the distribution (mean, standard deviation and $90^{\text {th }}$ percentile) of the maximal differences in posture variables for all participants.

Variation in horizontal eye position was $33.6( \pm 20.9) \mathrm{mm}$, higher than that of hip position (22 $\pm 14.5 \mathrm{~mm})$. Concerning preferred postural angles, trunk inclination to the vertical was the variable with the smallest variation with an average of $3.5( \pm 2.4)$ degrees, followed by trunkthigh angle, lower limb and upper limb related angles (knee, shoulder and elbow). The largest variation was found at the right elbow with an average of $10.7( \pm 6.3)$ degrees. 
Human Factors: The Journal of the Human Factors and Ergonomics Society

Table 5. Distribution of the maximum difference of postural variables (see Figure 3 for their definition) between three repetitions for all participants. Means, standard deviations and values at the $90^{\text {th }}$ percentiles are listed.

\begin{tabular}{|c|c|c|c|c|}
\hline Variables & unit & $90^{\text {th }}$ percentile & Mean & SD \\
\hline Hip_x & $\mathrm{mm}$ & 46.0 & 22.0 & 14.5 \\
\hline Eye_x & $\mathrm{mm}$ & 64.4 & 33.6 & 20.9 \\
\hline Eye_z & $\mathrm{mm}$ & 25.0 & 14.1 & 7.5 \\
\hline Trunk & $\circ$ & 7.2 & 3.5 & 2.4 \\
\hline R_Trunk-thigh & $\circ$ & 8.0 & 4.5 & 2.6 \\
\hline L_Trunk-thigh & $\circ$ & 8.0 & 4.6 & 2.4 \\
\hline R_Knee & $\circ$ & 11.1 & 5.6 & 3.3 \\
\hline L_Knee & $\circ$ & 14.4 & 7.3 & 4.7 \\
\hline R_Shoulder & $\circ$ & 11.5 & 6.0 & 3.6 \\
\hline L_Shoulder & $\circ$ & 10.3 & 5.5 & 3.1 \\
\hline R Elbow & $\circ$ & 21.6 & 10.7 & 6.3 \\
\hline L_Elbow & $\circ$ & 18.7 & 10.4 & 5.8 \\
\hline
\end{tabular}

Figure 4 compares intra and inter participant variability in the five postural angles. As expected, inter individual differences were much higher, implying a strong individual preference in postural angles.

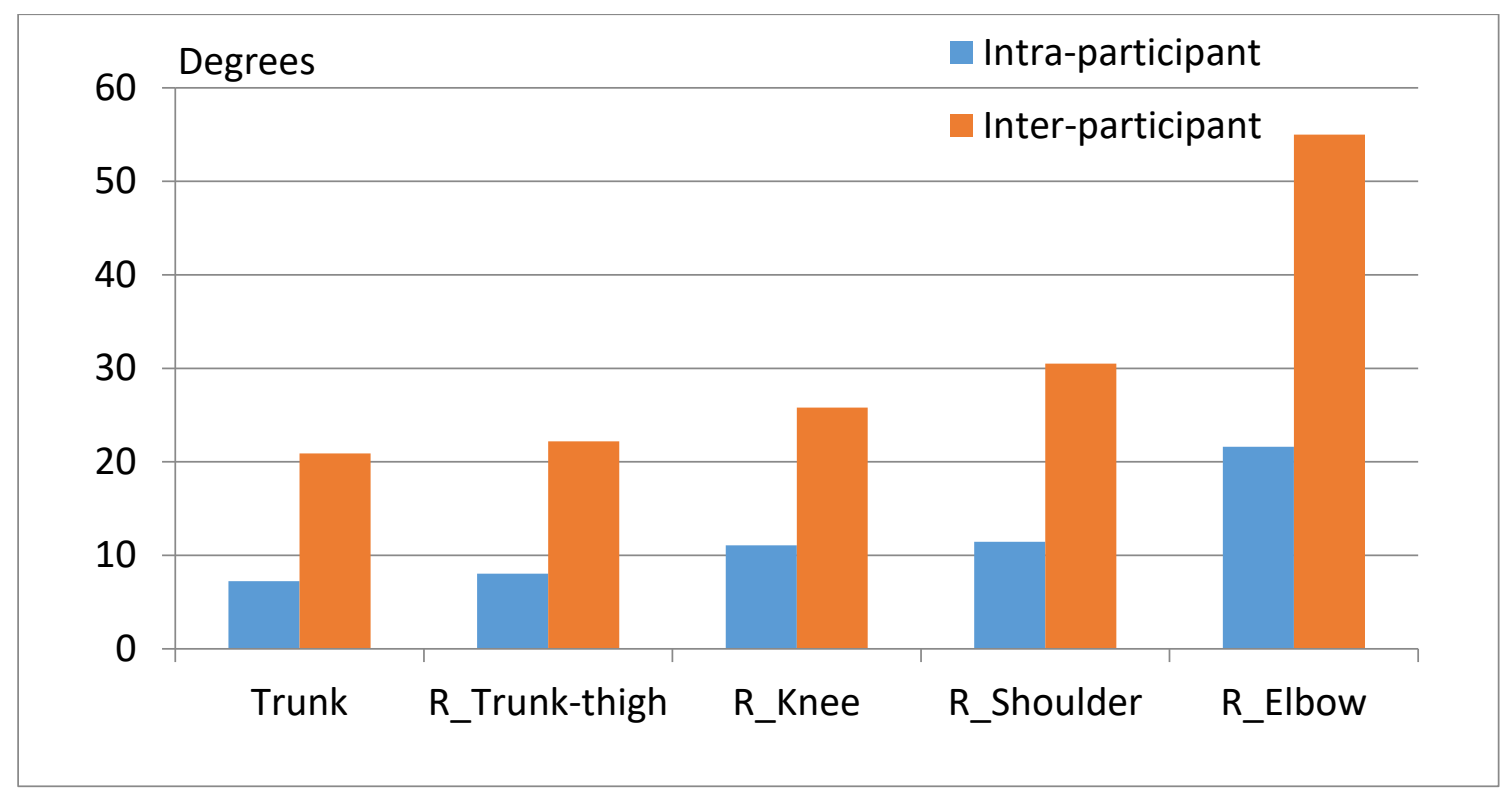

Figure 4. Intra and inter participant variability in preferred postural angles. Intra variability was defined as the $90^{\text {th }}$ percentile of the distribution of individual maximum differences between three repetitions of the trial with seat height of $300 \mathrm{~mm}$ among all participants. For inter invariability, the average of three repetitions for each participant was calculated. It was defined as the difference between $5^{\text {th }}$ and $95^{\text {th }}$ percentiles of the individual averages among all participants. 
Human Factors: The Journal of the Human Factors and Ergonomics Society

\section{Free seat height}

Table 6 gives the means and standard deviations of the preferred seat heights by stature group and initial seat height. Preferred seat height varied from 214.1 to $418.3 \mathrm{~mm}$, covering 95\% range of variation. It was strongly influenced by initial seat height. An initially low seat led to a low preferred height. A significant difference was found between three stature groups. The short participants adopted a seat height of $298.6 \mathrm{~mm}$ on average, significantly lower than two other groups. An interaction was found between stature group and initial seat height. The short participants preferred a much lower seat height than two other groups for an initially high seat, while for the initially low seat the three groups adopted almost the same seat height. No significant effect of participant group either by stature or by ethnic origin was found on intersegmental angles and trunk orientation as shown in Table 7.

Table 6. Means and standard deviations of the preferred seat heights in $\mathrm{mm}$ under FSH condition.

\begin{tabular}{cccc}
\hline & Initially low & Initially high & All \\
\hline Short & $285.5 \pm 33.3$ & $329.3 \pm 14.5$ & $298.6 \pm 35.2$ \\
Average & $281.5 \pm 36.2$ & $382.2 \pm 28.1$ & $336.9 \pm 60.1$ \\
Tall & $273.1 \pm 33.75$ & $383.3 \pm 22.4$ & $336.1 \pm 62.0$ \\
All & $280.9 \pm 33.5$ & $371.7 \pm 31.6$ & $324.1 \pm 56.0$ \\
& & & ISH $^{* * *}$, ISH $\times$ SG $^{*}$ \\
\hline
\end{tabular}

$* 0.01<$ P-value $<0.05 ; * * 0.001<$ P-value $<0.01 ; * * *$ P-value $<0.001$.

ISH: Initial seat height. ISH $\times$ SG : Interaction between stature group (SG) and initial seat height.

\section{Effect of seat height and anthropometric variables}

After the FSH condition, three seat heights fixed at 250, 300 and $350 \mathrm{~mm}$ were tested for each participant. The means and standard deviations of postural variables by seat height and subject group are given in Table 8 . The effects of seat height, subject group by stature or ethnic origin and their interaction are also indicated.

An increase in seat height of $100 \mathrm{~mm}$ resulted in an average forward movement of hip joint center of $23.4 \mathrm{~mm}$ and eye of $37.7 \mathrm{~mm}$, as well as an increase in trunk-thigh angle by $7.3^{\circ}$. Seat height had no effect on trunk and hip-to-eye angle. Concerning the effects of stature, an average difference of about $3^{\circ}$ in trunk orientation was observed between short and tall groups, whereas 
Human Factors: The Journal of the Human Factors and Ergonomics Society

a slightly smaller difference in hip-to-eye angle was found $\left(0.9^{\circ}\right)$. However, no significant difference in the other inter-segmental angles was found among three stature groups.

Compared to the French group, significant differences in trunk related angles were found for Chinese participants. Chinese group had a more reclined trunk angle by $1.9^{\circ}$ and a larger right trunk-thigh angle by $3.8^{\circ}$. The longitudinal offset (Hip_x-Seat_x) between the hip and seat $\mathrm{H}$-point was checked and showed that the Chinese had more forward hip location than the French participants. The Chinese group sat on average $33.4 \mathrm{~mm}$ further forward in the seat (see Figure 5). In order to ensure that this difference was not due to the posture reconstruction method by using RAMSIS model, hip joint centers were also calculated directly from measured marker positions which were attached at subject's skin during the experiments (See the method described in appendix). The same phenomenon was observed.

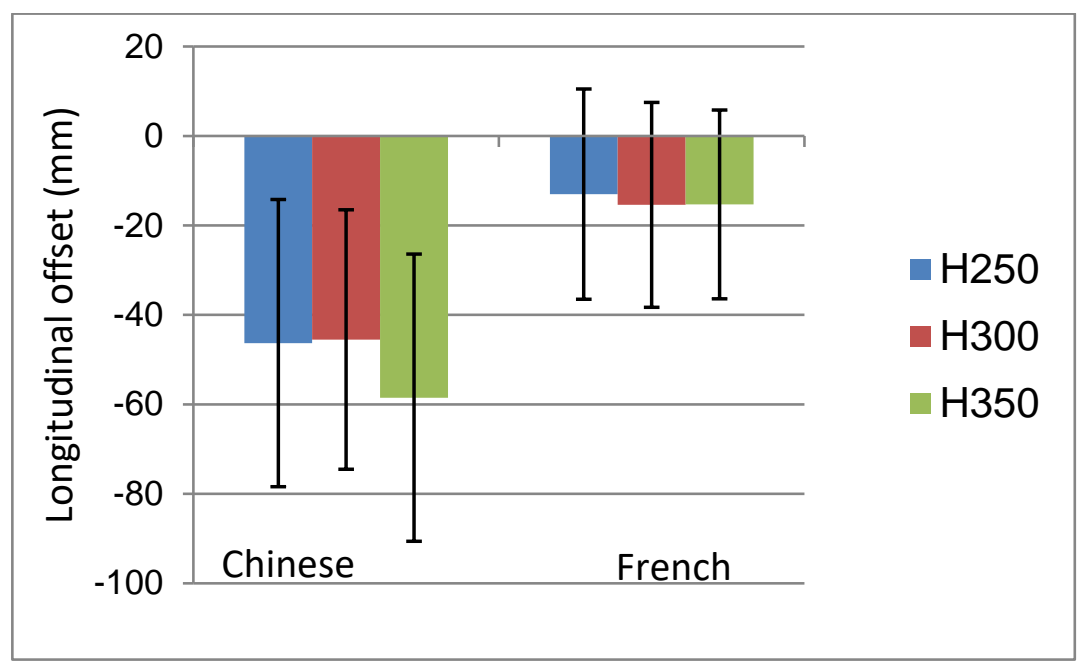

Figure 5. Longitudinal offset between hip joint center and seat H-point by ethnic group in three seat heights. Negative value means that the hip is more forward than H-point. Only participants with stature less than $1805 \mathrm{~mm}$ were considered 
Human Factors: The Journal of the Human Factors and Ergonomics Society

Table 7. Means and standard deviations of preferred postural angles in degrees under the FSH condition.

\begin{tabular}{|c|c|c|c|c|c|c|c|c|c|c|}
\hline & $\begin{array}{l}\text { Eye_x } \\
(\mathrm{mm})\end{array}$ & $\begin{array}{l}\text { Eye_z } \\
(\mathrm{mm})\end{array}$ & $\begin{array}{l}\text { Hip_x } \\
\text { (mm) }\end{array}$ & $\begin{array}{l}\text { Hip_z } \\
(\mathrm{mm})\end{array}$ & $\begin{array}{l}\text { Hip-to- } \\
\text { eye }\left(^{\circ}\right)\end{array}$ & $\begin{array}{l}\text { Trunk } \\
\left(^{\circ}\right)\end{array}$ & $\begin{array}{c}\text { R_Trunk- } \\
\text { thigh }\left(^{\circ}\right)\end{array}$ & $\begin{array}{c}\text { R_Knee } \\
\left(^{\circ}\right)\end{array}$ & $\begin{array}{c}\text { R_Shoulder } \\
\left(^{\circ}\right)\end{array}$ & $\begin{array}{c}\text { R_Elbow } \\
\left(^{\circ}\right)\end{array}$ \\
\hline Low & $893.6 \pm 115.5$ & $887.1 \pm 45.4$ & $797.4 \pm 91.8$ & $263.1 \pm 33.8$ & $8.9 \pm 4.3$ & $22.8 \pm 6.5$ & $92.05 \pm 7.9$ & $110.5 \pm 8.3$ & $54.5 \pm 8.5$ & $124.0 \pm 14.5$ \\
\hline High & $874.4 \pm 84$ & $1004.3 \pm 56$ & $809.1 \pm 63$ & $357.1 \pm 36.1$ & $5.9 \pm 4.7$ & $20.0 \pm 6.1$ & $93.6 \pm 5.7$ & $107.4 \pm 7.8$ & $52.4 \pm 8.9$ & $124.4 \pm 14.6$ \\
\hline Short & $804 \pm 50.6$ & $874.3 \pm 44.3$ & $731.4 \pm 39.1$ & $276 . \pm 43.9$ & $7.3 \pm 4.4$ & $20.0 \pm 6.8$ & $92.0 \pm 9.0$ & $109.3 \pm 8.1$ & $53.5 \pm 7.3$ & $119.4 \pm 13.7$ \\
\hline Average & $869.1 \pm 55.8$ & $960.7 \pm 66.6$ & $787.8 \pm 20.7$ & $322.6 \pm 57.9$ & $7.3 \pm 4.5$ & $21.8 \pm 5.6$ & $93.4 \pm 5.8$ & $108.2 \pm 6.1$ & $53.7 \pm 9.0$ & $125.2 \pm 15.0$ \\
\hline Tall & $975.8 \pm 99.8$ & $991 \pm 67$ & $885.5 \pm 66.1$ & $324 \pm 61.7$ & $7.8 \pm 5.3$ & $22.6 \pm 6.8$ & $92.9 \pm 5.9$ & $109.6 \pm 10.0$ & $53.3 \pm 9.9$ & $127.7 \pm 13.9$ \\
\hline Chinese & $841 \pm 70$ & $908 \pm 59.6$ & $755.2 \pm 55.6$ & $288.7 \pm 43.7$ & $8 \pm 4.2$ & $22.3 \pm 5.5$ & $93.5 \pm 7.6$ & $109.2 \pm 7.2$ & $54.1 \pm 9.1$ & $120 \pm 15.3$ \\
\hline French & $854.3 \pm 66.8$ & $943.9 \pm 81.2$ & $785.2 \pm 45.7$ & $310.7 \pm 64.6$ & $6.4 \pm 4.1$ & $19.6 \pm 6.1$ & $91.4 \pm 5.3$ & $108.7 \pm 6.0$ & $54.4 \pm 7.0$ & $122.5 \pm 11$ \\
\hline \multirow[t]{2}{*}{ All } & $884.5 \pm 101.4$ & $942.8 \pm 77.5$ & $802.9 \pm 79$ & $307.8 \pm 58.7$ & $7.5 \pm 4.7$ & $21.5 \pm 6.4$ & $92.8 \pm 7.0$ & $109.0 \pm 8.2$ & $53.5 \pm 8.7$ & $124.2 \pm 14.4$ \\
\hline & $\mathrm{SG} * * * \mathrm{SH}^{*}$ & $\mathrm{SH}^{* * *} \mathrm{SG}^{* *}$ & $\mathrm{OG} * \mathrm{SG} * * *$ & $\mathrm{SH}^{* * *} \mathrm{SG} *$ & $\mathrm{ISH}^{*}$ & $\mathrm{ISH}^{*}$ & & ISH* & & \\
\hline
\end{tabular}

$* 0.01<$ P-value $<0.05, * * 0.001<\mathrm{P}$-value $<0.01, * * * \mathrm{P}$-value $<0.001$

ISH: Initial seat height; SG: Stature group; OG: origin group 
Human Factors: The Journal of the Human Factors and Ergonomics Society

Table 8. Means and standard deviations of the preferred driving postural angles in degrees by seat height, stature and ethnic groups.

\begin{tabular}{|c|c|c|c|c|c|c|c|c|c|c|}
\hline & $\begin{array}{l}\text { EyeX } \\
(\mathrm{mm})\end{array}$ & $\begin{array}{l}\text { EyeZ } \\
(\mathrm{mm})\end{array}$ & $\begin{array}{l}\text { HipX } \\
(\mathrm{mm})\end{array}$ & $\begin{array}{l}\text { HipZ } \\
(\mathrm{mm})\end{array}$ & $\begin{array}{l}\text { Hip-to- } \\
\text { eye }\left(^{\circ}\right)\end{array}$ & $\begin{array}{l}\text { Trunk } \\
\left(^{\circ}\right)\end{array}$ & $\begin{array}{c}\text { R_Trunk- } \\
\text { thigh } \\
\left(^{\circ}\right)\end{array}$ & $\begin{array}{c}\text { R_Knee } \\
\left(^{\circ}\right)\end{array}$ & $\begin{array}{c}\text { R_Shoulder } \\
\left({ }^{\circ}\right)\end{array}$ & $\begin{array}{c}\text { R_Elbow } \\
\left(^{\circ}\right)\end{array}$ \\
\hline H250 & $932.5 \pm 102$ & $869.3 \pm 38$ & $826.3 \pm 77.6$ & $239.3 \pm 14.1$ & $9.5 \pm 4.4$ & $24.0 \pm 6.4$ & $91.1 \pm 7.4$ & $112.8 \pm 8.2$ & $53.3 \pm 9.7$ & $124.63 \pm 15.6$ \\
\hline Н300 & $910.6 \pm 98.0$ & $920.7 \pm 40.3$ & $816.3 \pm 78.3$ & $289.2 \pm 15.4$ & $8.5 \pm 4.5$ & $23.2 \pm 6.3$ & $94.4 \pm 7.2$ & $112.3 \pm 7.2$ & $52.4 \pm 9.1$ & $123.9 \pm 15.7$ \\
\hline H350 & $894.8 \pm 98.1$ & $969.3 \pm 45$ & $802.9 \pm 84.5$ & $338.6 \pm 16.3$ & $8.4 \pm 4.7$ & $23.2 \pm 6.5$ & $98.4 \pm 7.7$ & $112.2 \pm 7.4$ & $52.0 \pm 9.4$ & $125.6 \pm 16.0$ \\
\hline Short & $826.5 \pm 53.4$ & $876.6 \pm 38.4$ & $742 \pm 40$ & $281.3 \pm 34.4$ & $8.2 \pm 5.1$ & $21.8 \pm 7.8$ & $95.9 \pm 10.1$ & $113.6 \pm 8.1$ & $52.3 \pm 9.4$ & $120.6 \pm 16.3$ \\
\hline Average & $906.2 \pm 43.2$ & $926.2 \pm 39.3$ & $808.6 \pm 30.1$ & $291.7 \pm 33.9$ & $8.7 \pm 3$ & $23.8 \pm 4.1$ & $93.7 \pm 5.2$ & $110.7 \pm 6.1$ & $52.5 \pm 9.2$ & $124.1 \pm 15.9$ \\
\hline Tall & $1002.5 \pm 94.3$ & $957.9 \pm 39.7$ & $896.1 \pm 65$ & $294.6 \pm 35.5$ & $9.1 \pm 5.1$ & $24.5 \pm 6.3$ & $94.0 \pm 6.8$ & $112.8 \pm 7.6$ & $52.6 \pm 9.3$ & $128.5 \pm 14.0$ \\
\hline Chinese & $861.4 \pm 68.8$ & $906.8 \pm 48.1$ & $763.6 \pm 58.4$ & $292.7 \pm 36.2$ & $9.1 \pm 4.1$ & $23.9 \pm 6.0$ & $96.6 \pm 7.8$ & $112.6 \pm 7.7$ & $53.1 \pm 10.8$ & $121.5 \pm 17.3$ \\
\hline French & $890.7 \pm 63$ & $913.7 \pm 50.4$ & $803.1 \pm 44.6$ & $284.4 \pm 33.1$ & $8 \pm 4$ & $22.0 \pm 5.9$ & $92.8 \pm 7.4$ & $111.6 \pm 7.0$ & $52.6 \pm 8.4$ & $123.8 \pm 15.0$ \\
\hline \multirow[t]{4}{*}{ All } & $911.8 \pm 99.2$ & $920.1 \pm 51.6$ & $815.6 \pm 79.5$ & $289.1 \pm 35$ & $8.7 \pm 4.5$ & $23.4 \pm 6.4$ & $94.6 \pm 7.7$ & $112.4 \pm 7.4$ & $52.5 \pm 9.3$ & $124.4 \pm 15.7$ \\
\hline & $\mathrm{SG}^{* * *}$ & $\mathrm{SG}^{* * *}$ & $\mathrm{SG}^{* * *}$ & $\mathrm{SG}^{* * *}$ & $\mathrm{SG}^{*} \mathrm{OG}^{*}$ & $\mathrm{SG}^{*} \mathrm{OG}^{*}$ & $\mathrm{SH}^{* * *}$ & & & \\
\hline & $\mathrm{SH}^{* *}$ & $\mathrm{SH}^{* * *}$ & $\mathrm{SH}^{*}$ & $\mathrm{SH}^{* * *}$ & & & $\mathrm{OG}^{* * *}$ & & & \\
\hline & $\mathrm{OG}^{*}$ & & $\mathrm{OG}^{* * *}$ & & & & & & & \\
\hline
\end{tabular}

$* 0.01<$ P-value $<0.05, * * 0.001<\mathrm{P}$-value $<0.01, * * *$ P-value $<0.001$

$\mathrm{SH}$ : seat height; SG: stature group; OG; origin group 


\section{Discussion}

The effects of driver's anthropometric dimensions and seat height on preferred driving postures were investigated in the present work. As expected, much higher inter-individual variability in postural angles was found than intra-individual variability. Under the FSH condition, preferred seat height was largely dependent on the initially proposed height, and no significant differences in preferred inter-segmental angles were observed between different participant groups. Seat height principally affected trunk-thigh angle, while it had almost no effect on hip-to-eye, trunk orientation, knee, elbow and shoulder angles. Comparison between three stature groups only showed small but significant difference in trunk orientation under the condition of imposed seat heights. The short group tended to adopt a slightly less reclined trunk than two other groups. No effect of stature group was found on inter-segmental angles. However, comparison between two ethnic groups showed that Chinese participants adopted a more reclined trunk by $1.9^{\circ}$ and a more open trunk-thigh angle by $3.8^{\circ}$. Main observations will be compared with other studies and discussed in the following.

As stated recently by Schmidt et al (2013) in a review on preferred joint angles in automotive sitting posture, comparison between different studies is problematic due to differences in the methods used for estimating joint angles and also in the experimental conditions (e.g. instruction given to participants to place the hands on the steering wheel, number of available adjustments and their range, etc.). Being aware of this difficulty, Table 9 compares the angle ranges observed under the FSH condition in the present study with those recommended by some earlier studies. For trunk angle, the observed range $\left(18^{\circ}-43^{\circ}\right)$ by Kyung and Nussbaum (2009) and the min-max range observed in the present study $\left(10^{\circ}-40^{\circ}\right)$ are much larger than that recommended range $\left(20^{\circ}\right.$ to $\left.30^{\circ}\right)$ by Rebiffé (1969). Note that RAMSIS recommends an optimum trunk angle of $27^{\circ}$. Concerning trunk- thigh angle, the range observed in the present study ( $5^{\text {th }}$ to $95^{\text {th }}$ percentiles, $82^{\circ}-102^{\circ}$ ) is between those by Hanson et al (2006) and by Park et al (2000). Hanson et al (2006) observed a variation from $68^{\circ}$ to $99^{\circ}$ with the mid value much smaller than the present study. This may be due to the difference in the range of seat height adjustment. In Hanson's study, seat height (H30) varied from -20 to 265 mm while it could be adjusted from 150 to $500 \mathrm{~mm}$ in the present study under the FSH condition. Our results showed that trunk-thigh angle increased with seat height. For the knee angle, the range observed in the present study is within the ranges proposed by Rebiffé (1969), Porter and Gyi (1998) and also by Kyung and Nussbaum (2009), but quite different from that proposed by Park 
Human Factors: The Journal of the Human Factors and Ergonomics Society

et al (1999). The knee angle range by Hanson et al (2006) is much larger with its mid value much higher than the present study. For the elbow angle, quite different ranges were proposed with a much larger range of variation compared to other angles. Besides, Kyung and Nussbaum (2009) proposed two discontinued sub-range for each joint angle, which was not the case for other studies.

Table 9. Comparison of observed joint angles ranges (in degree) with other studies. For the purpose of comparison, all the joint angles in current study were calculated in 2-dimensions side view (sagittal plane).

\begin{tabular}{|c|c|c|c|c|c|c|}
\hline & Side & & Trunk & $\begin{array}{l}\text { Trunk- } \\
\text { thigh }\end{array}$ & Knee & Elbow \\
\hline Rebiffe(1969) & & & $20-30$ & $95-120$ & $95-135$ & $80-120$ \\
\hline Porter and Gyi(1998) & & $\min -\max$ & - & $90-115$ & 99-138 & $86-164$ \\
\hline Park et al. (1999) & & $\min -\max$ & - & $101-127$ & $120-151$ & $88-137$ \\
\hline Vogt et al. (2005) & & & 27 & 99 & 119 & 127 \\
\hline \multirow[t]{2}{*}{ Hanson et al. (2006) } & Left & $\min -\max$ & - & $92-109$ & $109-157$ & $96-160$ \\
\hline & Right & $\min -\max$ & - & 68-99 & & $98-163$ \\
\hline \multirow{4}{*}{$\begin{array}{l}\text { Kyung and Nussbaum } \\
\text { (2009) }\end{array}$} & Left & $\min -\max$ & $18-26$ & $79-87$ & $84-91$ & $85-120$ \\
\hline & & & $32-43$ & $107-118$ & $118-129$ & $146-165$ \\
\hline & Right & $\min -\max$ & Symmetric & 83-92 & $93-110$ & 85-108 \\
\hline & & & & $112-123$ & $123-142$ & $103-145$ \\
\hline \multirow[t]{4}{*}{ Current study } & Left & $5^{\text {th }}-95^{\text {th }}$ & $12-31$ & 80-102 & $95-122$ & $111-167$ \\
\hline & & $\min -\max$ & $10-40$ & $76-110$ & $93-130$ & $98-176$ \\
\hline & Right & $5^{\text {th }}-95^{\text {th }}$ & Symmetric & 83-102 & $97-122$ & $103-145$ \\
\hline & & $\min -\max$ & & 74-104 & $87-129$ & $92-162$ \\
\hline
\end{tabular}

Results showed that the preferred seat height was strongly affected by the initially given height. There was also a large intra-individual variability in preferred vehicle interior dimensions and driving postures for a given seat height. This implies that the driver's preferred posture for a person is not unique, but rather a range of postures within which a driver would not feel a noticeable difference in terms of comfort/discomfort.

No significant difference in the inter-segmental joint angles was found between three stature groups under the FSH condition. This is in agreement with the results of Ribouchon (1991) and Hanson et al. (2006). Only a slight but significant difference was found in trunk orientation between small and tall groups under the condition of three imposed seat heights. Short participants tended to adopt a slightly less reclined trunk than two other groups. This could be explained, at least partially, by the invariance of inter-segmental angles. If a short and a tall person adopt a same posture (with the same joint angles) for a same seat height, the shorter person has to rotate the body more forward in order to reach the accelerator pedal, leading to a 
Human Factors: The Journal of the Human Factors and Ergonomics Society

less reclined trunk. In spite of little difference in postural angles, the short drivers have more forward position of hip and eye than tall drivers, as illustrated in Figure 6

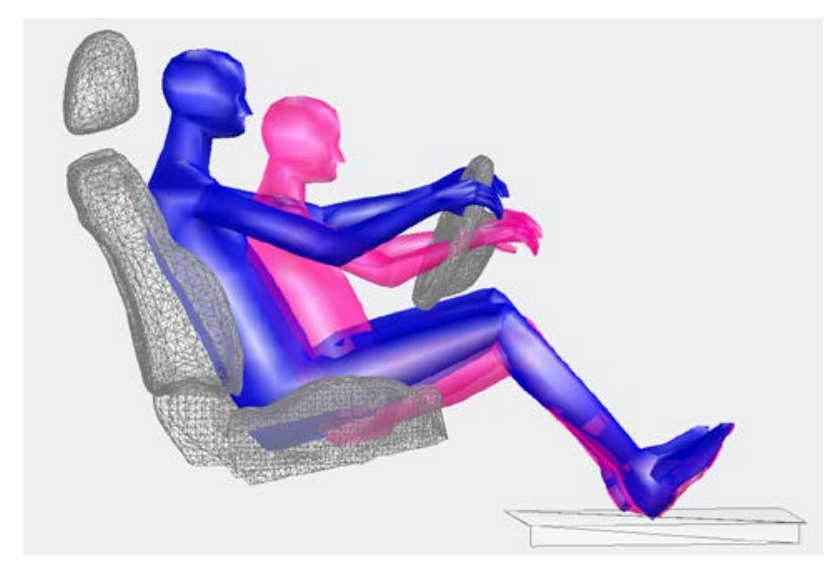

Figure 6 Illustration of the effect of stature on preferred posture at imposed seat height

As far as the effect of ethnic origin was concerned, it was observed that Chinese participants had a more forward hip location in the seat leading to a more open trunk-thigh angle and a more reclined trunk, as illustrated in Figure 7. One explanation could be the long seat cushion length used in this study and that the Chinese group had shorter buttock-knee length as shown in Table 2. The seat used in the present study had a minimum cushion length of $364 \mathrm{~mm}$, measured as horizontal distance from the seat front edge to the H-point, while Reed (2000) recommended that this distance should not be longer than $316 \mathrm{~mm}$ for accommodating a small female. Figure 8 presents the distribution of the offsets between hip joint center of reconstructed RAMSIS manikins and seat H-point at the seat height of $300 \mathrm{~mm}$ as function of buttock-knee length. The subjects with a buttock-knee length shorter than $570 \mathrm{~mm}$ except one tended to sit more forward in the seat. However, this cannot explain why those who had a long buttock-knee length also sat more forward than French subjects, as illustrated in Figure 8. 
Human Factors: The Journal of the Human Factors and Ergonomics Society

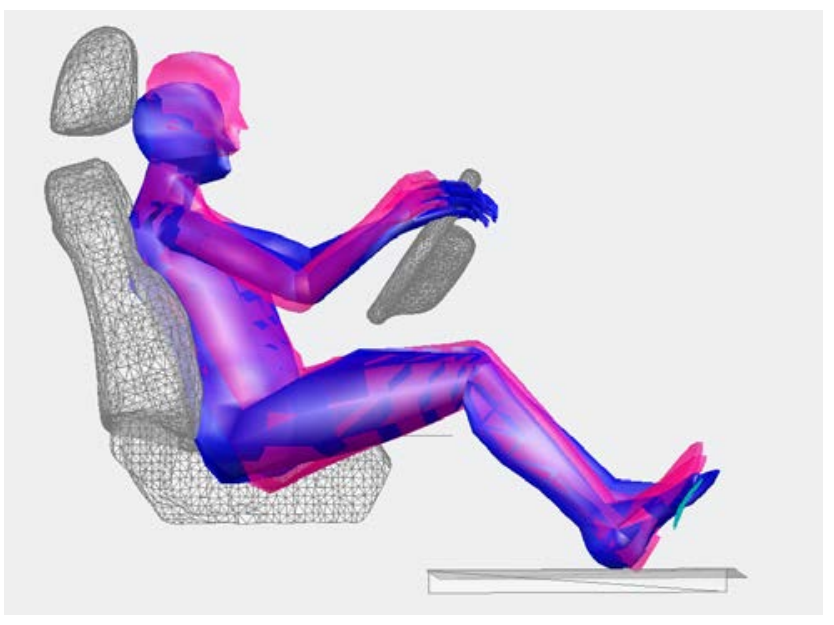

Figure 7. Illustration of the differences in posture in the rest position between a Chinese and a French subjects (In red: a Chinese with stature of $1745 \mathrm{~mm}$ and sitting height of $970 \mathrm{~mm}$; in blue: a French with stature of $1740 \mathrm{~mm}$ and sitting height of $860 \mathrm{~mm}$ ). The longitudinal position of the accelerator pedal was the same

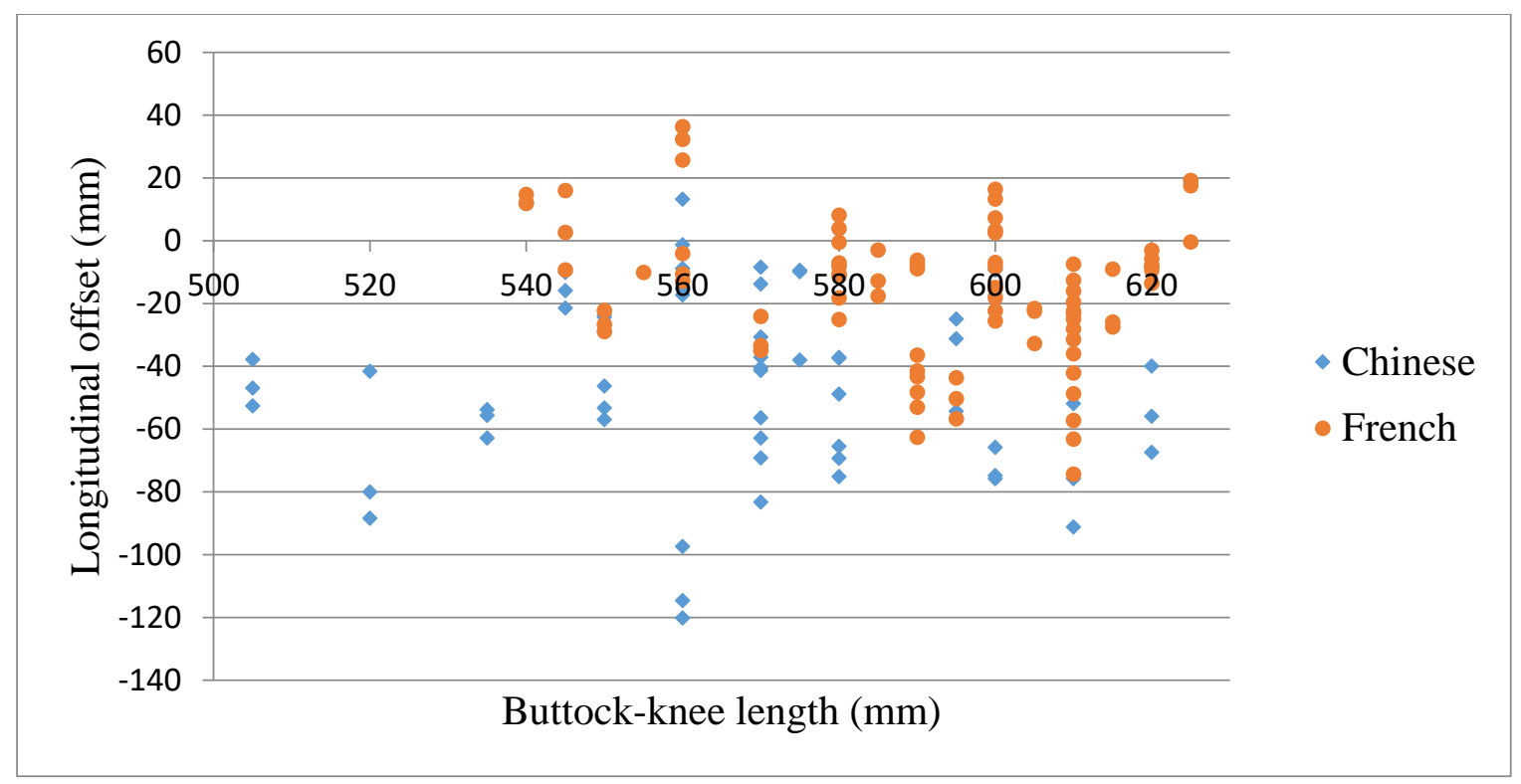

Figure 8 Longitudinal offset between hip joint center and seat H-point under imposed seat height of 300mm (three repetitions) as function of buttock-knee length of subjects

Concerning effect of seat height, only trunk-thigh angle was affected while other postural angles including trunk orientation remained little affected. If a person has to keep the same trunk orientation with respect to the vertical, knee angle and heel point, an increase of seat height would geometrically lead to a more open trunk-thigh angle. This is illustrated in Figure 9 comparing the postures at two seat heights for an average height person. Results from the present study confirm the observation by Reed et al (2000) that trunk orientation with respect to the vertical was quite invariant across different vehicle configuration. 

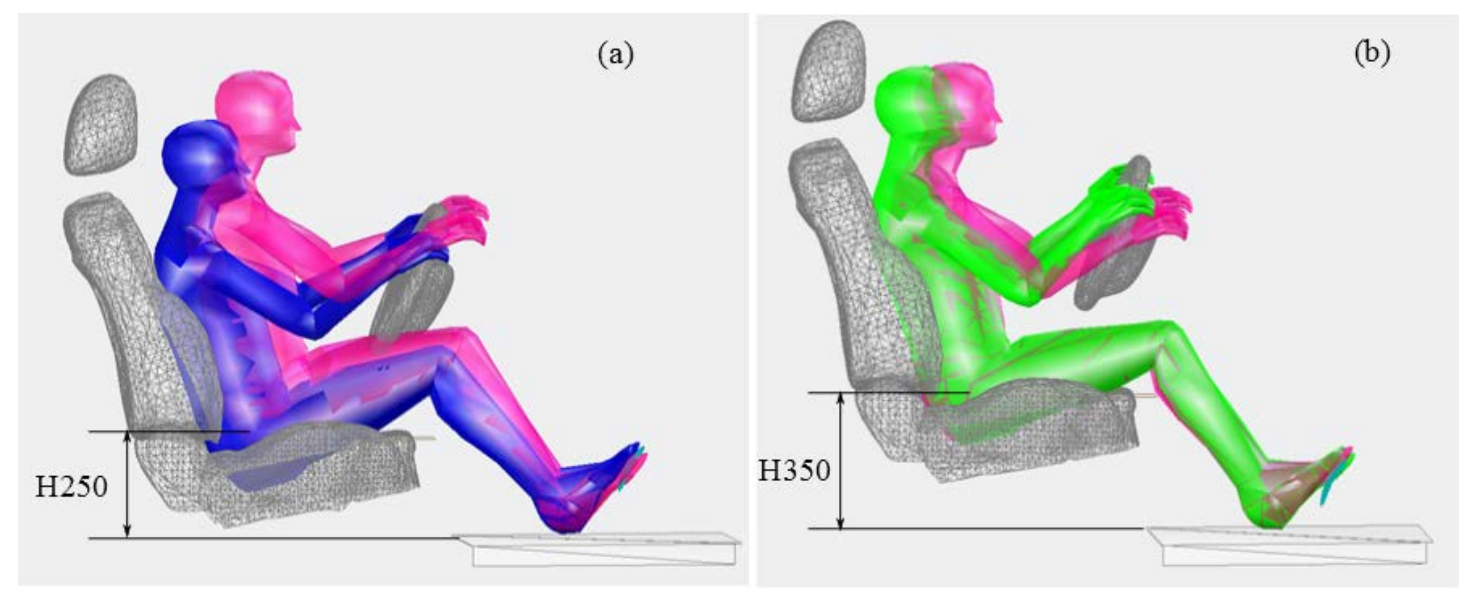

Figure 9. Illustration of the change of preferred driving posture at the rest when varying seat height from 250 to $350 \mathrm{~mm}$ for a subject of $1720 \mathrm{~mm}$. Postures in blue and in green are the observed postures for seat height of $250 \mathrm{~mm}$ and $350 \mathrm{~mm}$ respectively. The posture in red is obtained from the posture in blue after three operations while maintaining the same intersegmental angles:1) translation of $100 \mathrm{~mm}$ upward 2) rotation of $8^{\circ}$ around the pelvis so that the heels touch the floor 3)translation of $30 \mathrm{~mm}$ forward so that the right foot touches the accelerator pedal.

In the present work, the ranges of variation of inter segmental angles of preferred driving postures were obtained using a highly adjustable mock-up. Though vehicle designers are focused on the specifications of vehicle component positions and adjustments but not on 'comfortable joint angles', the specifications should be made such that drivers' postures should be 'comfortable', that is to say postural angles should be within their comfort range. Based on the data collected in the present research, we recently proposed a three color model based on intra and inter individual variability ranges of comfortable angles for assessing a vehicle interior (Peng et al. 2017), and verified that the model could be used for detecting potential problems of postural discomfort. Of course, a digital human modeling tool should be used for simulating driving posture. It should be noted that intra-individual variability were examined in the past and explored for improving product design (Park et al., 2012, Garneau and Parkinson, 2013). In the work by Park and his colleagues (2012), a numerical index based on intra-individual variability in drivers’ preferences was proposed to quantify a vehicle interior design.

Body posture could also be represented by the position of joint centers and relevant body landmarks. Inter-segmental angles were preferred in the present work because they are much more body size invariant. Of course, the preferred position of the hip and eyes could be useful. For reason of confidentiality, their regression equations are not included in the paper. This does 
Human Factors: The Journal of the Human Factors and Ergonomics Society

not affect the main observations and conclusions regarding the research questions raised in Introduction.

\section{Limitations}

Only one seat was used in this study and its long cushion might have influenced the hip position in the seat for short subjects. The effect of seat itself on the preferred driving posture requires further investigation. Another important limitation is that the experiment was carried out in the laboratory without considering the real road vision requirements and headroom clearance constraints. Preferred postures observed in present study could be considered as an optimum. Postures that a driver adopts in a real vehicle may certainly be different from his/her optimum. Vehicle interior should be designed to allow the majority of drivers to adopt the optimum postures.

In order to investigate the body segment proportion effect on driving posture, a big effort was made to recruit equal number of Chinese and French subjects in each stature groups (short, average and tall). However, nearly no tall Chinese participants were recruited because the experiment was carried out in France. It would be interesting to investigate the differences between Chinese and European drivers using a larger sample.

\section{Conclusions}

Considerable intra individual variability in preferred driving posture was observed, suggesting that there is no unique preferred posture and vehicle interior layout. Among all angular variables investigated in the present work, trunk orientation had the smallest intra individual variation and was not affected by seat height. Larger intra variability in other intersegmental angles especially in elbow angle suggests that the angles of the limbs especially those of the upper limb are less critical for postural comfort. Apart from trunk-thigh angle, intersegmental angles were largely unaffected by seat height. When seat height was freely adjustable, trunk-thigh angle tended to be the same regardless of stature group. Large inter participant variability in preferred inter-segmental angles is not explained by difference in anthropometric dimensions, showing a strong individual effect in choosing preferred driving posture. Our results support the assumption that the inter-segmental (joint) angles of preferred posture are not dependent on anthropometric dimensions though shorter drivers prefer a slightly less reclined trunk. Chinese participants seemed to sit more forward in the seat. This needs to be confirmed with a larger sample size of participants. Effects of seat characteristics especially cushion length need to be further investigated. 
Human Factors: The Journal of the Human Factors and Ergonomics Society

\section{Ackknoledgement}

The present study was partly supported by PEUGEOT CITROEN AUTOMOBILES (PCA).

\section{Key points}

- Large inter participant variability in preferred inter-segmental angles is not explained by difference in anthropometric dimensions, showing a strong individual effect in choosing preferred driving posture.

- Considerable intra individual variability in preferred driving posture was observed, suggesting that there is no unique preferred posture and vehicle interior layout.

- When seat height was freely fixed, preferred seat height was dependent on the initially proposed height, and no significant differences in preferred inter-segmental angles were observed between different participant groups.

- Seat height mainly affected trunk-thigh angle but not trunk orientation to the vertical.

- Small but significant difference in trunk orientation between three stature groups was observed under the condition of imposed seat heights. The short group tended to adopt a slightly less reclined trunk than two other groups. No effect of stature group was found on inter-segmental angles.

- Chinese participants seemed to sit more forward in the seat. But effects of seat characteristics especially cushion length need to be further investigated.

\section{References}

Ausejo, S. and Wang, X., (2009). Motion Capture and human Motions reconstruction. In:Duffy, V.G. (Ed), Handbook of Digital Human Modeling: Research for Applied Ergonomics and Human Factors Engineering. CRC Press, Inc., Boca Raton, FL, USA, 38-1-38-14.

GB10000 (1988). Human dimensions of Chinese adults. General Administration of Quality Supervision, Inspection and Quarantine of the People's republic of China

Duffy, V.G., 2009. Handbook of Digital Human Modeling: Research for Applied Ergonomics and Human Factors Engineering. CRC Press, Inc., Boca Raton, FL, USA.

Gordon, C.C., Churchill, T., Clauser, C. E., Bradtmiller, B. and McConville, J. T. (1989). 1988 Anthropometric survey of US army personnel: methods and summary statistics. Anthropology research project Inc yellow Springs $\mathrm{OH}$.

Garneau, Christopher J., and Matthew B. Parkinson. (2013) "Considering just noticeable difference in assessments 


\section{https://dx.doi.org/10.1177/0018720817741040}

\section{Human Factors: The Journal of the Human Factors and Ergonomics Society}

of physical accommodation for product design." Ergonomics 56(11), 1777-1788.

Hanson, L., Sperling, L. and Akselsson, R. (2006). Preferred car driving posture using 3-D information. International Journal of Vehicle Design, 42(1), 154-169

Rennesson, J.L. (2012). A Full Range of 3D Body Scanning Solutions, 3rd Int. Conf. on 3D Body Scanning Technologies, pp164-170.

Kyung, G. (2008). An integrated human factors approach to design and evaluation of the driver workspace and interface. Thesis, Virginia Polytechnic Institute and State University

Kyung, G. and Nussbaum M.A. (2009). Specifying comfortable driving postures for ergonomic design and evaluation of the driver workspace using digital human models. Ergonomics, 52(8), 939-953.

Pannetier, R. and Wang, X. (2014). A comparison of clutching movements of freely adjusted and imposed pedal configurations for identifying discomfort assessment criteria. Applied ergonomics, 45(4), 1010-1018.

Park, S.J., Kim, C.B., Kim, C.J. and Lee, J.W. (2000). Comfortable driving posture for Koreans. International Journal of Industrial Ergonomics, 26(4), 489-497.

Park, W., Min, C., Perdu, L., Escobar, C. (2012) Quantifying a vehicle interior design’s ability to accommodate drivers' preferences. Proceedings of the Human Factors and Ergonomics Society Annual Meeting. Vol. 56. No. 1. 2321-2325.

Park, J., Ebert S. M., Reed, M.P. (2016). Statistical models for predicting automobile driving postures for men and women including effects of age. Human Factors, 2016 Mar;58(2):261-78. DOI: 10.1177/0018720815610249

Peng, J., Panda, J., Jan, S.V.S., and Wang, X. (2015). Methods for determining hip and lumbosacral joint centers in a seated position from external anatomical landmarks. Journal of biomechanics, 48(2), 396-400.

Peng, J., Wang X. and Denninger, L. (2017). Ranges of the least uncomfortable joint angles for assessing automotive driving posture, Applied Ergonomics 61, 12-21

Porter, J.M. and Gyi D.E. (1998). Exploring the optimum posture for driver comfort. International Journal of Vehicle Design, 19 (3), 255-266.

Rebiffé, R., Guillien, J. and Pasquet, P. (1982). Enquête anthropométrique sur les conducteurs français. Laboratoire de physiologie et de biomécanique de l’association Peugeot-Renault. (in French).

Rebiffé, R. (1969) Le siège du conducteur :son adaptation aux exigences fonctionnelles et anthropométriques. Ergonomics, 12(2), 246-261 (in French).

Ribonchon, S., (1991) Confort postural du conducteur assis:etude des situations de confort optimal et des situation observées sous contrainte de h'auteurs d'assise. Thesis, Université de paris-sud, center d’Orsay, Paris, France (in French).

Reed, M.P., Manary, M.A., Flannagan, C.A. and Schneider, L.W. (2000). Effects of Vehicle Interior Geometry and Anthropometric Variables on Automobile Driving Posture. Human Factors, 42(4), 541-552.

Reed, M.P. (2000). Survey of auto seat design recommendations for improved comfort. Michigan Transportation Research Institute (UMTRI). http://mreed.umtri.umich.edu/mreed/pubs/Reed\%20Seating\%20Literature\%20Review\%202000.pdf

Reed, M. P., Manary, M. A., Flannagan, C. A. C., \& Schneider, L. W. (2002). A statistical method for predicting automobile driving posture. Human Factors, 44, 557-568

Schmidt, S., Amereller, M., Franz, M., Kaiser, R. and Schwirtz, A., (2014) A literature review on optimum and preferred joint angles in automotive sitting posture. Appl Ergon 45, 247-260. 
Human Factors: The Journal of the Human Factors and Ergonomics Society

Seidl, A., (1994). Das Menschmodell RAMSIS, Analyse, Synthese und Simulation Dreidimensionaler Körperhaltung des Menschen. (The man model RAMSIS: Analysis, Synthesis and Simulation of Threedimensional Human Posture), Technical University of Munich, Germany, Doctoral thesis (in German).

Wang, X., Verriest, J.P., Lebreton-Gadegbeku, B., Tessier, Y. and Trasbot, J. (2000). Experimental investigation and biomechanical analysis of lower limb movements for clutch pedal operation. Ergonomics, 43(9), 14051429.

Vogt, C., Mergl, C. and Bubb, H., (2005). Interior layout design of passenger vehicles with RAMSIS. Human Factors and Ergonomics in Manufacturing \& Service Industries, 15(2), 197-212.

\section{Appendix}

\section{Estimation of hip joint center directly from markers}

- Step 1: Anatomical landmarks manual palpation.

Prior to driving posture session, each subject was asked to sit on a rigid table, looking forward with the trunk being upright and the arm crossed. A technique frame with four markers was attached to the pelvis. Five anatomical landmarks (ALs) were manually palpated: Right anterior superior iliac spine (RIAS), Right posterior superior iliac spine (RIPS), Left posterior superior iliac spine (LIPS), Left anterior superior iliac spine (LIPS), Pubic symphysis (IPJC), as shown in Figure 10. A global coordinate system method (GCS) was used to estimate the hip joint center by using the RIAS, LIAS, RIPS and IPJC for the right hip joint center (RHJC) and LIAS, RIAS LIPS and IPJC for the left hip joint center (Peng et al. 2015).

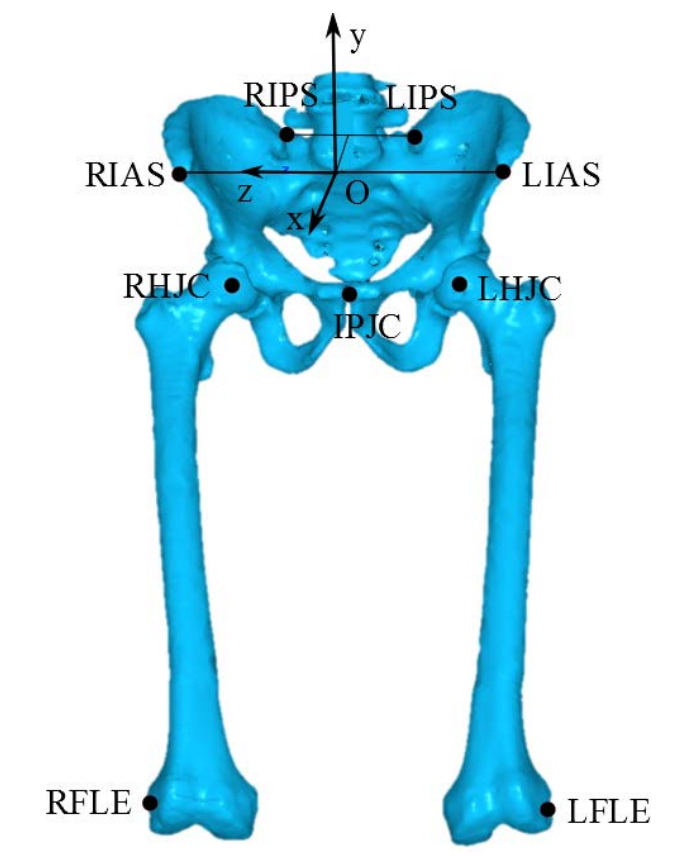

Figure 10 Illustration of anatomical landmarks of pelvis and femur 
Human Factors: The Journal of the Human Factors and Ergonomics Society

\section{- Step 2: Distance estimation}

Four markers were attached on the pelvis and femurs at the four ALs (RIAS, LIAS, RFLE and LFLE). The subject was asked to sit on a stool and adopt a posture close to driving posture. The positions of markers were then recorded by Vicon motion system. The two hip joint centers were relocated with help of the pelvis technique frame. Three distances of each side between hip center and markers were computed: DRIAS-RHJC, DLIAS-RDHJ and DRFLE-RHJC for the right hip.

\section{- Step 3: Hip joint center location estimation in an automotive seat.}

From the captured positions of the four markers (RIAS, LIAS, RFLE, and LFLE) when seated in an automotive seat during the experiment, the hip joint center was calculated by an optimization procedure:

$$
\text { minimize } f(\boldsymbol{C})=\sum_{i=1}^{3}\left(\sqrt{\boldsymbol{C}-\boldsymbol{T}_{i}}-d_{i}\right)^{2}
$$

where C is the hip joint center; $\boldsymbol{T}_{i}(i=1: 3)$ is the measured locations of three markers for each side: RIAS, LIAS and RFLE (for the right); $\boldsymbol{d}_{i}(i=1: 3)$ are the distances between hip joint center and corresponding markers obtained in the step 2.

\section{Biographies}

Junfeng Peng is a research engineer at Decathlon. He received a $\mathrm{PhD}$ in biomechanics from Université Claude Bernard Lyon 1 in 2015.

Xuguang Wang is a senior researcher at French Institute of Science and Technology for Transport, Development and Network. He recieved a PhD in solid mechanics from Ecole Centrale de Lyon in 1991 and his HDR (Habilitation à Diriger des Recherches) from Université Claude Bernard Lyon 1 in 2008.

Lisa Denninger is an expert in physical ergonomics in PSA Peugeot Citroën. She received a PhD in Biomechanics from Ecole Nationale Supérieure d'Arts et Métriers (ENSAM) in 2001. 